\title{
Complement activation and blockade in massive post-partum haemorrhage, thrombotic microangiopathy and acute kidney injury: a case report
}

\author{
G. Guzzo ${ }^{1,2,3^{*}}$ (D, S. Kissling ${ }^{4}$, G. Pantaleo ${ }^{3}$, M. Pascual ${ }^{2}$, S. Sadallah ${ }^{3}$ and D. Teta ${ }^{1}$
}

\begin{abstract}
Background: Thrombotic microangiopathy (TMA)-mediated acute kidney injury (AKI) following massive haemorrhage is a rare but severe complication of the post-partum period. It is associated with a poor renal prognosis and a high risk of end-stage kidney disease. Complement activation may occur in this picture. However, whether complement activation, and thus complement blockade, may be critically relevant in this setting is unknown.

Case presentation: A 50 year-old woman presented with massive delayed post-partum haemorrhage (PPH). Despite bleeding control and normalization of coagulation parameters, she rapidly developed AKI stage 3 associated with dysmorphic microhematuria and proteinuria up to $2 \mathrm{~g} /$ day with the need of renal replacement therapy. Blood tests showed signs of TMA associated with markedly increased sC5b-9 and factor Bb plasma levels, respectively markers of terminal and alternative complement pathway over-activation. This clinical picture prompted us to initiate anti-C5 therapy. sC5b-9 normalized within $12 \mathrm{~h}$ after the first dose of eculizumab, factor $\mathrm{Bb}$ and $\mathrm{C} 3$ after seven days, platelet count after nine days and haptoglobin after 3 weeks. The clinical picture improved rapidly with blood pressure control within $48 \mathrm{~h}$. Diuresis resumed after three days, kidney function rapidly improved and haemodialysis could be discontinued after the sixth and last dose. Serum creatinine returned to normal two years after presentation.
\end{abstract}

Conclusions: We suggest that massive PPH induced major activation of complement pathways, which ultimately lead to TMA-induced AKI. Various causes, such as oocyte-donation, the potential retention of placental material and the use of tranexamic acid may have contributed to complement activation due to $\mathrm{PPH}$. The prompt administration of anti-C5 therapy may have rapidly restored kidney microcirculation patency, thus reversing signs of TMA and AKI. We propose that complement activation may represent a major pathophysiological player of this complication and may provide a novel therapeutic avenue to improve renal prognosis in TMA-induced AKI following massive PPH.

Keywords: Acute kidney injury (AKI), Bb factor, Complement activation, Complement blockade, Eculizumab, Postpartum haemorrhage (PPH), sC5b-9, Thrombotic microangiopathy (TMA), Case report

\footnotetext{
* Correspondence: gabriella.guzzo@hopitalvs.ch

${ }^{1}$ Service of Nephrology, Valais Hospital, Avenue du Grand-Champsec 86, 1950 Sion, Switzerland

${ }^{2}$ Organ Transplant Center, Lausanne University Hospital, University of Lausanne, Rue du Bugnon 46, 1011 Lausanne, Switzerland

Full list of author information is available at the end of the article
}

C C The Author(s). 2021 Open Access This article is licensed under a Creative Commons Attribution 4.0 International License, which permits use, sharing, adaptation, distribution and reproduction in any medium or format, as long as you give appropriate credit to the original author(s) and the source, provide a link to the Creative Commons licence, and indicate if changes were made. The images or other third party material in this article are included in the article's Creative Commons licence, unless indicated otherwise in a credit line to the material. If material is not included in the article's Creative Commons licence and your intended use is not permitted by statutory regulation or exceeds the permitted use, you will need to obtain permission directly from the copyright holder. To view a copy of this licence, visit http://creativecommons.org/licenses/by/4.0/ The Creative Commons Public Domain Dedication waiver (http://creativecommons.org/publicdomain/zero/1.0/) applies to the data made available in this article, unless otherwise stated in a credit line to the data. 


\section{Background}

Thrombotic microangiopathy (TMA) is a rare but severe complication of pregnancy and post-partum period [1]. Different noxious stimuli may trigger thrombi formation into small vessels leading to thrombocytopenia, anemia due to erythrocyte fragmentation and ischemic tissue damage [2]. Acute kidney injury (AKI) is a frequent consequence of TMA and is associated with a poor longterm renal prognosis [3].

Massive post-partum haemorrhage $(\mathrm{PPH})$ may be a cause of TMA-mediated AKI, mimicking post-partum pregnancy-associated atypical haemolytic uremic syndrome ( $\mathrm{p}$-aHUS). However, severe AKI occurring after massive $\mathrm{PPH}$ is multifactorial and may be precipitated by other factors including anti-fibrinolytic drugs through impairment of the patency of the kidney microcirculation [4]. Complement activation during massive $\mathrm{PPH}$ and TMA is an interesting finding, but its clinical significance remains unclear. We report the case of a massive $\mathrm{PPH}$ with dialysis-dependent AKI, TMA, and complement activation successfully treated with anti-C5 therapy.

\section{Case presentation}

A 50 year-old woman was admitted in our hospital for abdominal pain and massive vaginal haemorrhage. She was at day 9 post-partum, following a non-complicated elective caesarean section after unsuccessful birth induction. This event occurred after a 41 weeks normal gestation resulting from oocyte donation for infertility due to physiological ovarian aging. At admission, blood pressure was maintained at $129 / 91 \mathrm{mmHg}$ despite massive bleeding. Haemoglobin was $93 \mathrm{~g} / \mathrm{L}$ with a normal thrombocyte count. She rapidly underwent two uterine curettages followed by embolization of uterine arteries. Treatment also included amines, oxytocine, sulprostone, $2 \mathrm{~g}$ of tranexamic acid (TXA), 5 units of packed red blood cells (RBC), 1 unit of platelets, 2 units of frozen plasma and $2 \mathrm{~g}$ of fibrinogen for consumption coagulopathy. At Intensive Care Unit admission, serum creatinine was increased to $116 \mu \mathrm{mol} / \mathrm{L}$ and platelet count was decreased to $102 \mathrm{G} / \mathrm{L}$. Due to persistent uncontrolled bleeding, she underwent total hysterectomy, with the administration of 7 additional RBCs and $500 \mathrm{mcg}$ of TXA. Total blood loss was estimated to $2700 \mathrm{~mL}$. Anatomopathological analysis of surgical tissues excluded signs of endometritis. In the recovery room, she developed symptomatic high blood pressure associated with blurred vision, dizziness, headache and hyperreflexia necessitating intravenous labetalol. Despite bleeding control and coagulation markers' normalization, haemoglobin, platelet count and kidney function continued to worsen, subsequently leading to AKI stage 3 associated with dysmorphic microhematuria and proteinuria up to $2 \mathrm{~g} /$ day with the need of replacement therapy. Blood tests showed numerous schizocytes (49\%) with undetectable haptoglobin $(<0.1 \mathrm{~g} / \mathrm{L})$ and massive lactate dehydrogenase (LDH $1340 \mathrm{UI} / \mathrm{L}$ ) levels, clearly defining signs of TMA. Disseminated intravascular coagulation was reasonably ruled out due to a normal fibrinogen level. ADAMTS-13 activity was normal at 38\%, although the essay was performed just after the administration of the 2 initial fresh frozen plasma packs. C3 was reduced to $0.63 \mathrm{~g} / \mathrm{L}$ with markedly increased serum sC5b-9 and $\mathrm{Bb}$ factors, respectively to $637 \mathrm{ng} / \mathrm{ml}$ (normal range $127-$ $303 \mathrm{ng} / \mathrm{mL}$ ) and $5.95 \mu \mathrm{g} / \mathrm{mL}$ (normal range $<1.65 \mu \mathrm{g} /$ $\mathrm{mL})$. Moreover, a serum C3 splitting activity was found giving rise to $\mathrm{C} 3 \mathrm{c}$. Factor $\mathrm{H}(\mathrm{FH})$ was normal and Factor I (FI) was slightly but not significantly reduced to $36.2 \mu \mathrm{g} / \mathrm{mL}$ (normal range $38-58 \mu \mathrm{g} / \mathrm{mL}$ ), probably due to consumption. No anti-FH antibody was detected (Table 1). The marked activation of complement alternative and terminal pathways prompted us to start anti-C5 therapy, i.e. intravenous eculizumab $900 \mathrm{mg}$, once weekly, with the required antibiotic prophylaxis and meningococcal vaccination. Interestingly, $\mathrm{sC} 5 \mathrm{~b}-9$ normalized within $12 \mathrm{~h}$ after the first dose of eculizumab, factor $\mathrm{Bb}$ and $\mathrm{C} 3$ after seven days, platelet count after nine days and haptoglobin after 3 weeks. The clinical picture improved rapidly with blood pressure control after $48 \mathrm{~h}$ and diuresis resumed after three days. Weekly eculizumab was continued aiming a $\mathrm{CH} 50$ below $10 \%$. The patient received a total of six doses of eculizumab over two months, until haemodialysis could be discontinued (Fig. 1). Using Next-Generation Sequencing, no complement genetic abnormality in favour of $\mathrm{p}$-aHUS was detected. Two years after admission, the patient was doing well. Serum creatinine was $82 \mu \mathrm{mol} / \mathrm{l}$, corresponding to an estimated GFR of $71 \mathrm{ml} / \mathrm{min} / 1.73 \mathrm{~m}^{2}$ (CKDEPI Cystatine $C$ ), without proteinuria nor haematuria.

\section{Discussion and Conclusions}

We report the case of a woman with massive $\mathrm{PPH}$, TMA-induced AKI and complement major activation, which was not due to a deficit of main regulators of the complement alternative pathway, nor to an anti-Factor $\mathrm{H}$ antibody. Genetic screening did not reveal complement variants known to be associated with aHUS. A limitation of our report is the absence of kidney biopsy testifying renal cortical necrosis. This could not be performed due to the patient's critical conditions. However, in the context of a clear diagnosis of TMA, associated with markedly increased $\mathrm{Bb}$ and sC5b-9 factor plasma levels, demonstrating alternative and terminal complement pathway activation, kidney biopsy was not considered as essential for the patient's clinical management.

A recent paper published by Luc Frimat and Alexandre Hertig analysed retrospectively 105 cases of post- 
Table 1 Functional and genetic complement analysis at admission and during follow-up

\begin{tabular}{|c|c|c|c|c|c|c|}
\hline & Day 0 & Day+ 1 & Day+ 5 & Day+ 8 & 2nd week & After 9 months \\
\hline C3 (normal value $0.76-1.46 \mathrm{~g} / \mathrm{L}$ ) & $0.62(\downarrow)$ & - & - & 1.04 & 1.08 & - \\
\hline C4 (n.v. $0.1-0.4 \mathrm{~g} / \mathrm{L}$ ) & $0.07(\downarrow)$ & - & - & 0.16 & 0.18 & - \\
\hline CH50 (n.v. 70-140\%) & $61(\downarrow)$ & - & $1(\downarrow)$ & $13(\downarrow)$ & $2(\downarrow)$ & 74 \\
\hline MBL (n.v. > 49\%) & $0(\downarrow)$ & - & $5(\downarrow)$ & $3(\downarrow)$ & $0(\downarrow)$ & - \\
\hline AP50 (n.v. > 71\%) & $44(\downarrow)$ & - & $2(\downarrow)$ & $6(\downarrow)$ & $1(\downarrow)$ & 76 \\
\hline C5b-9 (n.v. 127-303 ng/mL) & $637(\uparrow)$ & 296 & 245 & 225.6 & - & $71(\downarrow)$ \\
\hline Bb factor (n.v. $<1.65 \mu \mathrm{g} / \mathrm{mL}$ ) & $5.95(\uparrow)$ & - & $2.43(\uparrow)$ & 1.45 & 0.98 & 0.78 \\
\hline H factor (n.v. $400-800 \mu \mathrm{g} / \mathrm{mL}$ ) & 723 & - & 700 & - & 803 & - \\
\hline I factor (n.v. $38-58 \mu \mathrm{g} / \mathrm{mL}$ ) & 36.2 & - & 48.5 & - & 45.8 & - \\
\hline B factor (n.v. 213-622 $\mu \mathrm{g} / \mathrm{mL}$ ) & 308.4 & - & - & - & - & - \\
\hline Anti-factor $\mathrm{H}$ (n.v. $<30 \mathrm{AU} / \mathrm{mL})$ & $<3.9$ & - & - & - & - & - \\
\hline C3 conversion & present & - & - & - & - & absent \\
\hline
\end{tabular}

No genetic abnormality was found in these complement and coagulation genes: ADAMTS13, C3, MCP, CFB, CFD, CFH, CFHR1, CFHR2, CFHR3, CFHR4, CFHR5, CFI, CFP, HOXA2, MMACHC, THBD

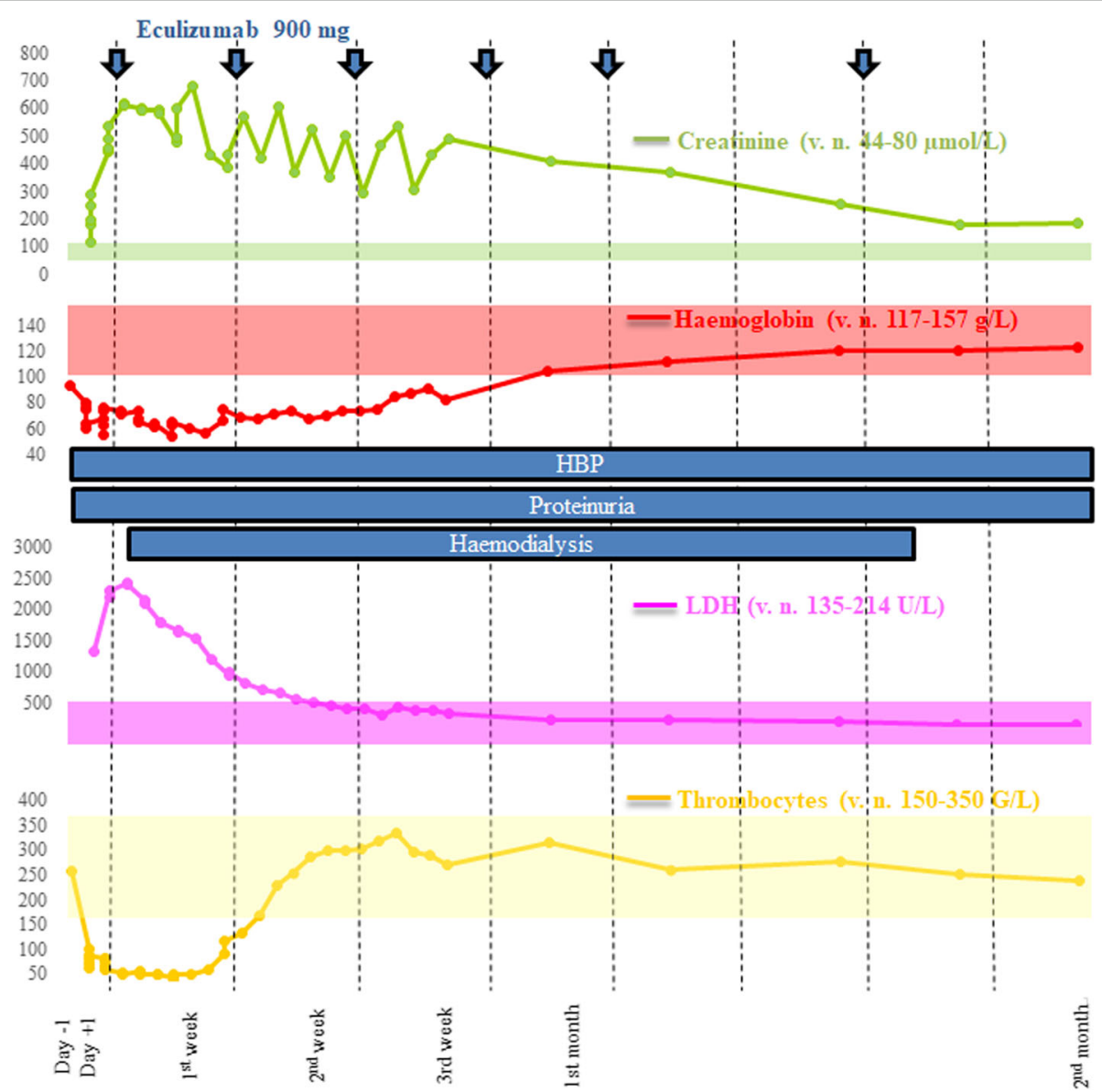

Fig. 1 Laboratory and clinical evolution from admission to the end of eculizumab administration. Normal values of creatinine, hemoglobin, LDH and thrombocytes are specified in the figure but also represented by transparent rectangles with the same colors of lines. Eculizumab administration are represented with thick blue arrows. HBP = high blood pressure controlled by therapy 
partum AKI, admitted in 9 different French intensive care units from 2011 to 2015 [5]. In 14 cases, AKI was attributed to TMA, and in 1 of these 14 patients, TMA was associated with PPH. AKI was related to $\mathrm{PPH}$ in 33 women; however, platelets counts rapidly improved at day 3 among these patients, unlike in TMA. Figure 1 clearly shows that our patient had persistently low platelet count after AKI onset, in line with the diagnosis of TMA. Our observation suggests that massive hemorrhage could be an alternative trigger of complement activation in cases of TMA not mediated by genetic or acquired predisposition to aHUS (Fig. 2).

Complement and coagulation cascades mutually belong to the first line of defence against noxious stimuli and descend from a common ancestor. Different animal experimental models showed that haemorrhagic shock can activate complement $[6,7]$. Furthermore, complement depletion with anti-C5 therapy or cobra venom factor improved post-resuscitation parameters in experimental model of haemorrhagic shock [6, 8]. In a prospective cohort of 208 adult trauma patients, complement activation and amplification by the alternative pathway, demonstrated by C5b-9 and Bb factor increased levels, were correlated with injury severity, tissue hypoperfusion and worse clinical outcomes, including acute kidney injury [9]. The precise molecular pathway of the cross talk between both cascades remains to be elucidated [10,
11]. Thrombin, factors IXa, Xa, XIa, and plasmin, appear to directly activate complement subunits $\mathrm{C} 3$ and C5, and independently of each other [12, 13]. Kallikrein, similarly to factor $\mathrm{D}$, cleaves $\mathrm{C} 3 \mathrm{bB}$ generating the alternative pathway $\mathrm{C} 3$-convertase (C3bBb) [14].

Various causes may have contributed to complement activation because of $\mathrm{PPH}$ in this case. Oocyte-donation has been associated with a higher incidence of $\mathrm{PPH}$ but its direct role in complement activation has not been investigated [15]. Retention of placental material may have contributed as a cause of delayed $\mathrm{PPH}$, since complete uterine revision was made difficult due to the abundance of material found. A retrospective analysis of $18 \mathrm{PPH}$ patients complicated by AKI proposed that TXA use was associated with renal cortical necrosis. We propose that TXA which is known to inhibit plasmin and the enzymatic breakdown of fibrinogen and fibrin may have delayed the clearance of vascular microthrombi, and thus TMA resolution [16, 17]. Compared to Frimat's case series, in which only two patients showed a significant improvement of kidney function at six months and eight remained dialysis-dependent, our patient showed a dramatically better kidney outcome. We suggest that administration of anti-C5 therapy may have prompted the recovery of microcirculation patency and subsequent AKI resolution. In addition, the rapid normalization of sC5b-9 and $\mathrm{Bb}$ factor levels, ahead of clinical improvement, appears in line with our hypothesis.

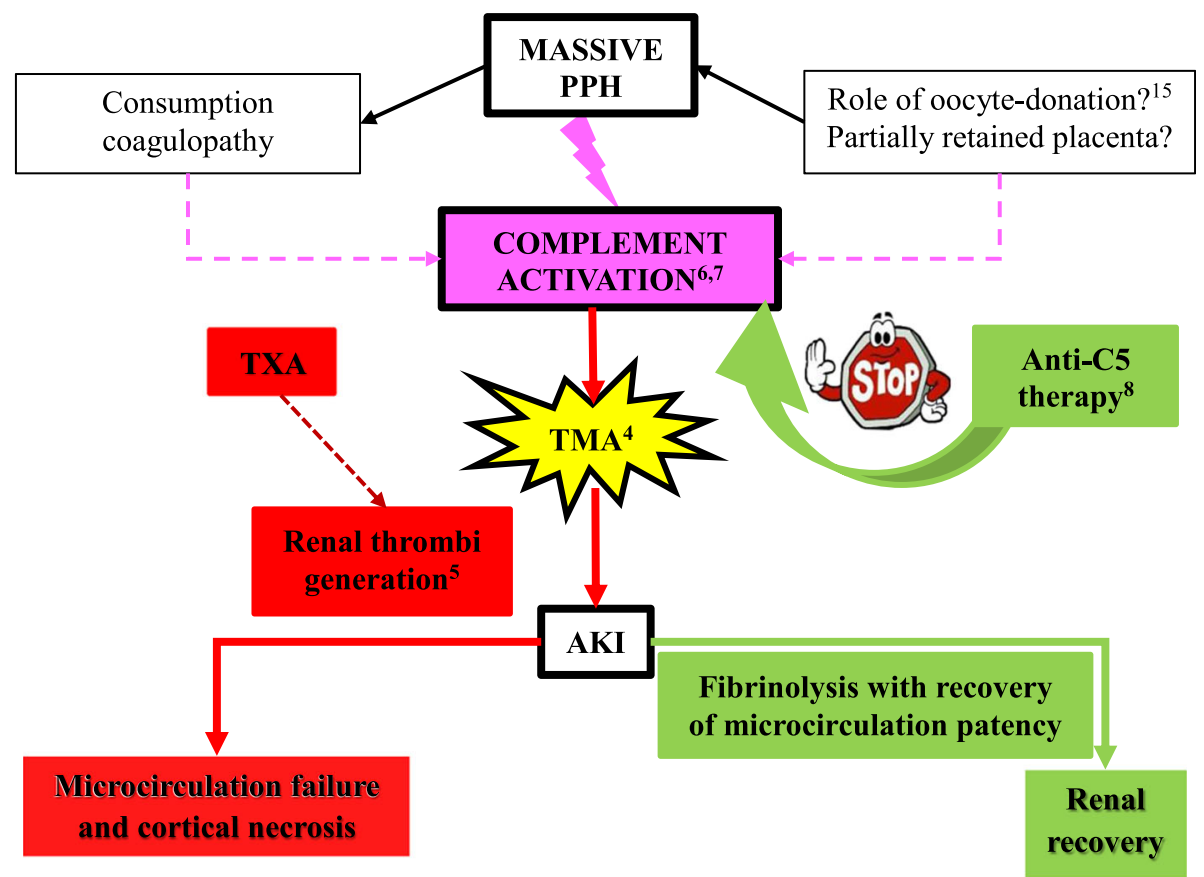

Fig. 2 Proposed physio-pathological mechanisms for complement activation in TMA induced-AKI following PPH, with subsequent application of anti-C5 therapy. Blue dotted arrows for potential mechanisms or relations 
In conclusion, we suggest to explore complement pathways systematically in patients with PPH and TMAinduced $\mathrm{AKI}$. In the case of $\mathrm{sC} 5 \mathrm{~b}-9$ and $\mathrm{Bb}$ factor elevations, the administration of anti-C5 therapy may prompt rapid normalization of $\mathrm{sC} 5 \mathrm{~b}-9$ and thus the recovery of microcirculation patency and subsequent AKI.

\section{Abbreviations}

AKI: Acute kidney injury; ESKD: End-stage kidney disease; FH: Factor $\mathrm{H}$; Fl: Factor I; LDH: Lactate dehydrogenase; p-aHUS: Pregnancy-associated atypical haemolytic uremic syndrome; PPH: Post-partum haemorrhage; RBC: Red blood cells; TMA: Thrombotic microangiopathy; TXA: Tranexamic acid

\section{Acknowledgements}

We would like to thank Dr. Garcia Martinez Juan José who took care of the patient in the Intensive Care Unit, and who first suspected a TMA-mediated AKI. We also thank our colleagues Dr. Anne-Hélène Reboux and Dr. Grzegorz Nowak, who contributed in the clinical management of the patient.

\section{Authors' contributions}

GG coordinated and supervised data collection, and drafted the initial and the revised manuscripts. SK brought critical comments to this case report. DT revised both the initial manuscript and the revised manuscript. SS performed the complement analysis, and contributed in writing the manuscript. All authors, including GP and MP, read and approved the manuscript.

\section{Funding}

No funding to declare.

\section{Availability of data and materials}

The authors declare that all main data supporting the findings of this study are available within the article.

\section{Declarations}

\section{Ethics approval and consent to participate}

Not applicable to case reporting. We did not conduct an experimental study. We described and reported the clinical management of this special case.

\section{Consent for publication}

The patient has been informed. The consent for publication has been signed from the patient (March 6, 2021)

\section{Competing interests}

The authors declare that they have no competing interests.

\section{Author details}

${ }^{1}$ Service of Nephrology, Valais Hospital, Avenue du Grand-Champsec 86, 1950 Sion, Switzerland. ºrgan Transplant Center, Lausanne University Hospital, University of Lausanne, Rue du Bugnon 46, 1011 Lausanne, Switzerland. ${ }^{3}$ Service of Immunology and Allergy, Lausanne University Hospital, University of Lausanne, Lausanne, Switzerland. ${ }^{4}$ Service of Nephrology and Hypertension, Lausanne University Hospital, University of Lausanne, Lausanne, Switzerland.

Received: 17 March 2021 Accepted: 17 June 2021

Published online: 06 July 2021

\section{References}

1. Fakhouri F, Vercel C, Fremeaux-Bacchi V. Obstetric nephrology: AKI and thrombotic microangiopathies in pregnancy. Clin J Am Soc Nephrol. 2012; 7(12):2100-6. https://doi.org/10.2215/CJN.13121211.

2. Brocklebank V, Wood KM, Kavanagh D. Thrombotic Microangiopathy and the Kidney. Clin J Am Soc Nephrol. 2018;13(2):300-17. https://doi.org/10.221 5/CJN.00620117

3. Hildebrand AM, Liu K, Shariff SZ, Ray JG, Sontrop JM, Clark WF, et al. Characteristics and outcomes of AKI treated with dialysis during pregnancy and the postpartum period. J Am Soc Nephrol. 2015;26(12):3085-91. https:// doi.org/10.1681/ASN.2014100954.
4. Frimat $M$, Decambron $M$, Lebas C, Moktefi A, Lemaitre L, Gnemmi V, et al. Renal cortical necrosis in postpartum hemorrhage: a case series. Am J Kidney Dis. 2016;68(1):50-7. https://doi.org/10.1053/j.ajkd.2015.11.022.

5. Meibody $F$, Jamme $M$, Tsatsaris $V$, Provot $F$, Lambert J, Frémeaux-Bacchi $V$, et al. Post-partum acute kidney injury: sorting placental and non-placental thrombotic microangiopathies using the trajectory of biomarkers. Nephrol Dial Transplant. 2020;35(9):1538-46. https://doi.org/10.1093/ndt/gfz025.

6. Younger JG, Sasaki N, Waite MD, et al. Detrimental effects of complement activation in hemorragic shock. J Appl Physiol (1985). 2001;90(2):441-6. https://doi.org/10.1152/jappl.2001.90.2.441.

7. Szebeni J, Baranyi L, Savay S, et al. Complement activation during hemorrhagic shock and resuscitation in swine. Shock. 2003;20(4):347-55. https://doi.org/10.1097/01.shk.0000082444.66379.17.

8. Peckham RM, Handrigan MT, Bentley TB, et al. C5-blocking antibody reduces requirements and improves responsiveness to fluid infusion in hemorrhagic shock managed with hypotensive resuscitation. J Appl Physiol (1985). 2007; 102(2):673-80. https://doi.org/10.1152/japplphysiol.00917.2006.

9. Ganter MT, Brohi K, Cohen MJ, Shaffer LA, Walsh MC, Stahl GL, et al. Role of the alternative pathway in the early complement activation following major trauma. Shock. 2007;28(1):29-34. https://doi.org/10.1097/shk.0b013e31 80342439.

10. Kenawy HI, Boral I, Bevington A. Complement-coagulation cross-talk: potential mediator of the physiological activation of complement by low pH. Front Immunol. 2015;6:215. https://doi.org/10.3389/fimmu.2015.00215.

11. Amara U, Rittirsch $D$, Flierl $M$, et al. Interaction between the coagulation and complement system. Adv Exp Med Biol. 2008;632:71-9. https://doi.org/10.1 007/978-0-387-78952-1_6.

12. Huber-Lang M, Sarma JV, Zetoune FS, Rittirsch D, Neff TA, McGuire SR, et al. Generation of $\mathrm{C} 5 \mathrm{a}$ in the absence of $\mathrm{C} 3$ : a new complement activation pathway. Nat Med. 2006;12(6):682-7. https://doi.org/10.1038/nm1419.

13. Amara U, Flierl MA, Rittirsch D, Klos A, Chen H, Acker B, et al. Molecular intercommunication between the complement and coagulation systems. J Immunol. 2010:185(9):5628-36. https://doi.org/10.4049/jimmunol.0903678.

14. Discipio RG. The activation of the alternative pathway C3 convertase by human plasma kallikrein. Immunology. 1982;45(3):587-95 PMID: 6916710; PMCID: PMC1555245.

15. Shrim A, Levin I, Mallozzi A, Brown R, Salama K, Gamzu R, et al. Does very advanced maternal age, with or without egg donation, really increase obstetric risk in a large tertiary center? J Perinat Med. 2010;38(6):645-50. https://doi.org/10.1515/jpm.2010.084.

16. CRASH-2 trial collaborators, Shakur $H$, Roberts I, Bautista $R$, et al. Effects of tranexamic acid on death, vascular occlusive events, and blood transfusion in trauma patients with significant haemorrhage (CRASH-2): a randomised, placebo-controlled trial. Lancet. 2010:376(9734):23-32. https://doi.org/10.101 6/S0140-6736(10)60835-5.

17. WHO. WHO recommendations for the prevention and treatment of postpartum haemorrhage. Geneva: World Health Organization; 2012.

\section{Publisher's Note}

Springer Nature remains neutral with regard to jurisdictional claims in published maps and institutional affiliations.

Ready to submit your research? Choose BMC and benefit from:

- fast, convenient online submission

- thorough peer review by experienced researchers in your field

- rapid publication on acceptance

- support for research data, including large and complex data types

- gold Open Access which fosters wider collaboration and increased citations

- maximum visibility for your research: over $100 \mathrm{M}$ website views per year

At BMC, research is always in progress.

Learn more biomedcentral.com/submission 